\title{
DO INDESEJÁVEL AO IMPONDERÁVEL: A EXPERIÊNCIA DE PROFISSIONAIS DE ENFERMAGEM FRENTE A MORTE
}

DOI: 10.22289/2446-922X.V7N2A15

\author{
Cristiano de Jesus Andrade ${ }^{1}$ \\ Carlos de Sousa Filho \\ Michelle Fonseca do Lago \\ Bruno Chapadeiro Ribeiro
}

\section{RESUMO}

Esta pesquisa objetivou analisar as percepções de enfermeiros quanto a morte dos pacientes em tratamento oncológico. Tal estudo valeu-se do método qualitativo, do tipo estudo de caso, tendo como sujeitos 10 enfermeiros oncológicos, com os quais foi utilizada a entrevista semiestruturada como técnica. Buscando analisar os resultados à luz da psicodinâmica do trabalho, a partir da qual pode-se compreender que os profissionais, identificam a morte como um processo natural, frequentemente vivenciado em sua profissão. No entanto apontaram vivenciarem tristeza e frustração mediante ao desligamento do paciente. Concluindo que embora os profissionais demonstrem lidar com a finitude de modo "natural", também experimentam sentimentos desconfortáveis, porém não adoeceram, visto que as defesas utilizadas garantem a integridade do ego em contato com a realidade.

Palavras-chave: Enfermagem oncológica; Cuidados de Enfermagem; Saúde do Trabalhador.

\section{FROM THE UNDESIRABLE TO THE IMPOSSIBLE: THE EXPERIENCE OF NURSING PROFESSIONALS IN THE FACE OF DEATH}

\begin{abstract}
This research aimed to analyze the perceptions of nurses regarding the death of patients undergoing cancer treatment. This study used the qualitative method, of the case study type, with 10 cancer nurses as subjects, with whom the semi-structured interview was used as a technique. Seeking to analyze the results in light of the psychodynamics of work, from which it can be understood that professionals identify death as a natural process, often experienced in their profession. However, they pointed out that they experience sadness and frustration due to the patient's withdrawal. Concluding that although professionals demonstrate to deal with finitude in a "natural" way, they also experience uncomfortable feelings, but they did not get sick, as the defenses used ensure the integrity of the ego in contact with reality.
\end{abstract}

Keywords: Oncology Nursing; Nursing Care; Occupational Health.

\footnotetext{
${ }^{1}$ Endereço eletrônico de contato: cristianoandradepsico@gmail.com

Recebido em 28/06/2021. Aprovado pelo conselho editorial para publicação em 09/10/2021.
} 


\section{DE LO INDESEABLE A LO IMPOSIBLE: LA EXPERIENCIA DE LOS PROFESIONALES DE ENFERMERÍA ANTE LA MUERTE}

\section{RESUMEN}

Esta investigación tuvo como objetivo analizar las percepciones de los enfermeros sobre la muerte de pacientes sometidos a tratamiento oncológico. Este estudio utilizó el método cualitativo, del tipo estudio de caso, con 10 enfermeras oncológicas como sujetos, con quienes se utilizó como técnica la entrevista semiestructurada. Buscando analizar los resultados a la luz de la psicodinámica del trabajo, a partir de la cual se puede entender que los profesionales identifican la muerte como un proceso natural, muchas veces vivido en su profesión. Sin embargo, señalaron que experimentan tristeza y frustración debido a la abstinencia del paciente. Concluyendo que si bien los profesionales demuestran lidiar con la finitud de manera "natural", también experimentan sentimientos incómodos, pero no enferman, ya que las defensas empleadas aseguran la integridad del yo en contacto con la realidad.

Palabras clave: Enfermería Oncológica; Atención de Enfermería; Salud Laboral.

\section{INTRODUÇÃO}

A morte é um fenômeno que sempre instigou a curiosidade humana, porém mesmo sendo sempre acompanhado de um desejo por saber, o mesmo acaba por suscitar no sujeito o medo de entrar em contato com a sua própria finitude (Benites, Neme, \& Santos, 2017; Bosco, 2008).

Dentre os profissionais que estão muito próximos da morte e do morrer em sua atuação cotidiana, vale demarcar os profissionais de enfermagem que serão contemplados por esta pesquisa. Nesse sentido, alguns estudos apontam que embora a morte seja parte do ciclo natural da vida, especificamente os(as) enfermeiros(as) que atuam em atendimento a pacientes oncológicos, geralmente, se colocam de modo angustiado mediante a finitude (Mota, Gomes, Coelho, Lunardi, \& Sousa, 2011; Sanches, 2007; Santana, Andrade, \& Carvalho, 2018). Nesta perspectiva, do confronto com a morte surgem frequentemente mais problemas psicológicos do que físicos na vida dos(as) enfermeiros(as) (Bezerra, Freitas, Lima, Fontoura, \& Oliveira, 2019; Braitt Lima \& Rosa, 2008). Assim, os mais mencionados são: pensamentos involuntários dedicados ao doente, sentimentos de impotência, choro e sensação de abatimento, sentimento de choque e de incredulidade perante a perda, dificuldades de concentração, cólera, ansiedade e irritabilidade. 
Aprofundando, Kübler-Ross (2008), por meio da observação e estudo a partir de entrevistas, conjecturou a existência de padrões de fantasias, comportamentos e ansiedades que podem experimentar o profissional de saúde mediante a ameaça de morte de seus pacientes. Em sua descrição, ela os agrupou em cinco estágios alguns mecanismos dos pacientes que estão ligados a compreensão destes da possibilidade de sua finitude, a partir dos quais podem passar, desde o momento em que se constata o diagnóstico da possível morte do paciente, sendo que em vários casos e situações, a sequência pode não ser exatamente essa devido a singularidade da experiência do paciente:

Negação: defesa psíquica que implica recusar o contato com um fato que promoveria turbulência e sofrimento emocional. Essa defesa não somente é perfeitamente compreensível, como pode ser necessária, por vezes impedindo uma desestruturação mental, desde que o profissional dê conta de cumprir com suas atribuições.

Raiva: quando não mais pode negar, ou o impacto sentido foi tão grande que a negação se tornou impossível; ele se sente tomado pelo ódio e pode demonstrar seu inconformismo por condutas violentas. Mostra-se agressivo e desafiador, atacando tudo e todos.

Negociação: nesse estágio aceita a realidade, mas tenta efetuar barganhas, "acordos", que the possibilitem manter uma visão não totalmente realística dos fatos, ou negocia para poder aproveitar melhor o tempo que lhe resta, junto a pessoa.

Depressão: nesse estágio estará elaborando lutos. O luto pelas vivências agradáveis e pelas oportunidades não aproveitadas junto a este paciente.

Aceitação: a esse estágio chegam aqueles que superaram os anteriores, e a chance de que isso ocorra é maior se tiveram ajuda durante todo o ciclo de elaboração do luto.

Tais modos a partir dos quais se experiencia a morte, podem ser notados em enfermeiro(a), os(as) quais para evitarem lidar com os sentimentos provocados pela morte e o morrer, desligam-se do doente e da ideia de que este irá falecer (Braitt Lima \& Santa Rosa, 2018; Bretas, Oliveira, \& Yamaguti, 2006). Buscando assim, consciente e/ou inconscientemente, concentrar a sua atenção no seu trabalho, no material, no processo da doença, talvez até em conversas superficiais, com o intuito de afastar expressões de temor e de morte.

Deste modo, este afastamento afetivo pode ser nomeado não como uma falta do desejo de auxílio ao paciente acometido, mas sim como mecanismos de defesa que este encontra para preservar seu ego (Andrade, Galhiarde, \& Avoglia, 2020; Campos, 2013; Ferracioli, Vendruscolo, \& Santos, 2017).

Rev. Psicol Saúde e Debate. Out., 2021:7(2): 236-252. 
Essa posição é destacada por Aguiar, Veloso, Pinheiro e Ximenes (2006) e Santana et al. (2018), em estudos que mostram que a convivência diária com o morrer pode fazer com que os profissionais encarem a morte com naturalidade, ou ainda frieza e indiferença. Na tentativa de se proteger, os(as) enfermeiros(as) buscam isolar seus medos e angústias, ou seja, cria-se certa regra que descreve que o bom profissional não deve se envolver. Assim, não tendo espaço para expressar emoções e angústias, o profissional nega seus sentimentos (Braitt Lima \& Santa Rosa, 2017; Gomes, Xavier, Salvador, Silveira, \& Barlem, 2014; Rocha, Nascimento, Raimundo, Damasceno, \& Bondim, 2017).

Diante do exposto, este trabalho ${ }^{1}$ tem como objetivo analisar as percepções dos(as) enfermeiros(as) acerca da morte e do processo de morrer dos pacientes em tratamento oncológico, e identificar os principais sentimentos e emoções experimentados pelo profissional mediante ao processo de desligamento do paciente.

\section{MATERIAS E MÉTODOS}

Para alcançarmos os objetivos anteriormente apresentados, utilizamos fundamentalmente o método clínico do tipo "estudo de caso" com base nos princípios teóricometodológicos da psicodinâmica do trabalho de Dejours. Portanto, trata-se de um estudo que se assenta nos princípios qualitativos-descritivos. Turato (2003) aponta que os métodos qualitativos possuem cerca de um século, vindo à luz dos estudos antropológicos, culturais e psicanalíticos. $O$ autor postula ainda que para o pesquisador qualitativo não bastam os fatos (os dados), mas é preciso a imaginação enquanto abertura como uma possibilidade de se interpretar o observado, para assim, compreender o que eles querem dizer para o sujeito e para a cultura em uma investigação.

Vizzotto (2003) traduz o método clínico salientando que a grosso modo, significa curvarse sobre o leito e, de início observar e descrever. A autora mostra que a lógica proposta pelo método clínico de abordagem psicanalítica perpassa um movimento espiral, isto porque, ao curvarmos sobre o fenômeno, observamos o que ocorre, descrevemos, levantamos hipóteses diagnósticas e, após, se intervêm. Continua-se então observando os resultados e a avaliar a eficiência da intervenção; e, novamente, observamos, são levantadas novas hipóteses e há um prosseguimento. A autora nos chama atenção para a importância do campo de ação, do

\footnotetext{
1 Vale apontar que esta pesquisa foi financiada pela Coordenação de Aperfeiçoamento de Pessoal de Nível Superior (CAPES).
}

Rev. Psicol Saúde e Debate. Out., 2021:7(2): 236-252. 
comportamento, da conduta (do que é manifesto e latente) dos indivíduos, dos grupos, da comunidade ou das instituições, onde o observador está presente e onde o observador se afasta ao mesmo tempo.

\section{Participantes}

A escolha dos participantes de pesquisa deliberou-se de uma amostra determinada com características definidas, ou seja, todos(as) enfermeiros(as) atuantes em serviço de oncologia (Turato, 2003).

Foram entrevistados(os) 10 enfermeiros(as), com idade entre 28 e 59 anos, profissionais com formação superior em enfermagem com emprego fixo na área de enfermagem oncológica, já que este foi um critério estabelecido para inclusão dos(as) participantes no estudo. Sendo que dentre estes(as), 06 são pós-graduados em oncologia, 03 em outra área e um não tem pós-graduação. No tocante ao tempo de serviço, os(as) participantes possuem de 02 a 20 anos de prática oncológica.

O tamanho final da amostra foi determinado pelo critério de saturação da informação. Saturação de informação é o processo no qual se interrompe o estudo quando os dados levantados tendem a repetir-se (Turato, 2003).

\section{Seleção dos participantes}

A priori, foi levantado o número de enfermeiros(as) atuantes junto as principais instituições na cidade de Poços de Caldas/MG e região. A amostra foi constituída a partir de convites feitos por um dos pesquisadores (Andrade) aos profissionais pessoalmente, por meio de visita nos seus locais de trabalho. Desta feita, foram entregues 43 convites, para os possíveis 43 participantes do município que eram graduados em enfermagem e atuavam em oncologia. Como critério de exclusão foram excluídos(as) enfermeiros(as) que trabalhavam no setor público e enfermeiros(as) com formação generalista, em virtude de o trabalho oncológico realizado por enfermeiros na região ser apenas oferecido por instituições de saúde privadas. Dos profissionais que preencheram os critérios apenas 10 aceitaram participar da pesquisa.

\section{Instrumento}

Como instrumento para se ter acesso aos dados, utilizou-se de entrevistas semidirigidas com duração de 50 minutos, as quais tiveram como norteador um roteiro para a caracterização dos participantes (socioeconômicas), no qual também continha uma questão disparadora "Você 
poderia me falar como percebe a morte de seus pacientes em tratamento oncológico?" . Salienta-se que, na dinâmica de trabalho estavam sendo consideradas as respostas emitidas dentro do contexto de uma questão disparadora anterior. Sendo respeitada uma sequência lógica sempre que possível. O roteiro foi submetido a um pré-teste antes de ser utilizado. Para fins de compreensão de sua eficácia, o mesmo foi testado em 03 participantes voluntários que também são da saúde, porém os mesmos não são contabilizados na amostra, por fazerem parte da testagem do instrumento.

A entrevista semidirigida foi escolhida para a coleta de dados, pois permite que o diálogo fosse mantido dentro do enfoque da pesquisa e ao mesmo tempo dá liberdade para que o sujeito exteriorize outras respostas relacionadas com o assunto.

Destarte, "a chave fundamental da entrevista está na investigação que se realiza durante o seu transcurso, observar, pensar e imaginar coincidem totalmente e formam parte de um só e único processo dialético" (Bleger, 2007, p. 18-19). É um comportamento integrado e único, pois inclui o que o entrevistador está recolhendo e já de uma forma que abrange a função de escutar, vivenciar e observar da pessoa entrevistada.

\section{Procedimentos}

Inicialmente, o projeto foi apresentado ao Comitê de Ética, após sua aprovação, publicada pelo parecer: 2.186 .446 2017. Para a realização da pesquisa, como pressuposto, foi apresentado o Termo de Consentimento Livre e Esclarecido para os(as) participantes do trabalho.

No processo de pesquisa a intimidade de cada participante esteve e continuará preservada, assim como os dados obtidos estarão sob pleno sigilo, tanto na coleta, análise e apresentação destes em forma de resultados do estudo, sendo garantida a não-identificação dos(as) participantes, com identificação pseudônima.

Os dados foram coletados pelo pesquisador (Andrade). Sendo feita a abordagem inicial e apresentado o Termo de Consentimento Livre Esclarecido, foi solicitada à permissão para uso do gravador no encontro. A gravação é uma forma de segurança no tocante a fidedignidade da informação obtida.

Cabe aqui explicar que as entrevistas em sua totalidade foram realizadas nos locais de trabalho dos(as) profissionais, visto a dificuldade em deslocá-los(as) para outros contextos. Contudo, a instituição ofereceu uma sala confortável, onde os mesmos(as) puderam associar livremente seus conteúdos. 


\section{Análise dos dados}

As entrevistas gravadas foram transcritas e foi feita uma segunda escuta para conferir a fidedignidade dos dados da transcrição.

Foram estabelecidas categorias de análise que foram identificadas nas leituras e releituras do conteúdo das entrevistas. As leituras e releituras foram realizadas dentro de um critério de atenção flutuante, isso significa que os pesquisadores ficaram atentos as evidências dos fenômenos (Turato, 2003). A análise será embasada na teoria da psicodinâmica do trabalho e com autores afins que dialogam com tal questão, sendo levados em consideração todos os aspectos observados a partir das entrevistas.

Os resultados foram apresentados por meio de categorias de análise, identificados no material coletado. Os mesmos serviram de base para uma posterior discussão com autores que tratam dos temas encontrados no levantamento de dados.

\section{RESULTADOS E DISCUSSÃO}

Conforme já salientado, os resultados serão apresentados em forma de duas principais categorias, sendo elas: profissionais de enfermagem frente a perda do paciente oncológico e sentimentos experimentados por profissionais de enfermagem frente ao processo de finitude do paciente em tratamento oncológico. Contudo, cada uma das categorias sinalizadas, se desdobram em subcategorias também representativas dos conteúdos que emergiram da investigação e que estão em forte dialogia com os objetivos do estudo.

\section{Profissionais de enfermagem frente a perda dos pacientes em tratamento oncológico}

Esta categoria busca apresentar como os profissionais compreendem a morte de seus pacientes em tratamento oncológico, bem como analisar suas formas de defesa mediante a finitude, além de descrever seus principais sentimentos vivenciados.

Para fins de compreensão, pode-se identificar que desde a construção do humano como sujeito, o mesmo aprende a lidar com duas concepções de morte: primeiramente a do outro, que remete a uma relação à angústia do abandono; e posteriormente a concepção da própria morte, a qual vem acompanhada de uma consciência de finitude, que é constantemente 
negada como um mecanismo de defesa, devido ao sofrimento gerado em falar de algo desconhecido e inevitável (Andrade et al., 2020; Bezerra et al., 2019; Ferreira \& Raminelli, 2012; Santana et al., 2018).

Os(as) participantes, predominantemente demonstraram lidar com a perda do paciente de modo "natural", salientando que tal fenômeno se dá em um processo de aprendizagem, ou seja, no "cotidiano" do trabalho. Contudo, tal aprendizagem, pode ser fruto de uma exigência inconsciente que os mesmos experimentam devido a profissão, que conforme apontam os participantes, faz com que tenham que "continuar", uma vez que mesmo "morrendo" um paciente e sendo algo "triste", outros pacientes "virão e é para estes que precisam "continuarem" (sic).

Como forma de ilustração, encontram-se as falas a seguir:

"Quando acontece a morte do paciente a gente fica triste! É uma situação que incomoda todos os profissionais, mas no dia seguinte já é vida nova, já é uma coisa que não incomoda tanto mais, por que nem pode incomodar, precisamos viver para outros pacientes." (G.).

"Assim, aprendo a lidar com a morte, como enfermeira a gente acaba encarando isso como um processo natural", "Não tenho limitação, para mim é tranquilo, natural porque como enfermeira lido de modo natural." (M.).

"Eu não sei se o tempo de profissão me deixou dura, ou um pouco realista, não falo insensível porque hoje eu chorei por causa de um paciente. Pela situação de um paciente. Mas eu sou uma pessoa muito conformada com a morte, eu não acho que a morte é pior solução, eu acho que a situação doença e a doença que você não tem o prognóstico é muito mais dolorosa para mim como profissional." (L.).

Tais relatos versam sobre o modo como os(as) enfermeiros(as) lidam com a morte e o morrer de seus pacientes. Assim, é evidenciada uma naturalização frente a possibilidade de finitude e respectivamente um manejo, a partir do qual tentam se organizar para manter o cuidado com novos pacientes, o que não quer dizer que não sejam afetados pela perda quando esta ocorre. Nesse sentido, a possibilidade da morte e o contato com a sua concretude é ainda uma questão "[...] muito difícil de ser encarada pelo ser humano, principalmente quando se trata da percepção de sua própria terminalidade" (Kübler-Ross, 2008, p.6).

A este modo, cabe pontuar que embora os(as) enfermeiros(as), lidem com a morte dos pacientes de maneira "natural", devido a influência do manejo profissional, no que tange a compreensão de sua própria finitude, os mesmos, demonstram-se resistentes em contatar os

Rev. Psicol Saúde e Debate. Out., 2021:7(2): 236-252. 
conteúdos inerentes a temáticas. Esta dificuldade em entrar em contato com a finitude pode estar ligada ao fato de a mesma vir a representar um processo de interrupção da existência, ou até mesmo uma "punição" (Campos, 2013). Conforme se exemplifica nos discursos a seguir:

"Uma privação de muitas coisas boas que eu poderia estar vivendo, se direcionado a minha pessoa e em certos momentos a gente acaba vendo como natural da vida, e que um dia a gente vai passar por isso. Em outros momentos a gente acha que é como uma punição, eu acho." (R.).

"Eu encaro a morte tranquilamente, mas não quero ver a minha por um bom tempo, sou bem tranquila quanto a isso." (C.).

Ampliando a discussão, ao contrário do que Bretas et al. (2006) apresenta, no tocante as limitações vivenciadas, os profissionais, participantes deste estudo trouxeram o vínculo com o paciente como um fator promotor de sofrimento psíquico. No processo de perda dos mesmos e não demonstraram resistência em contatá-los mesmo sabendo de sua eminente finitude.

Neste sentido, o vínculo pode ser concebido como um componente básico no processo interativo e é também a mola propulsora de todo o afeto que atravessa as relações, seja de ordem pessoal, ou profissional (Andrade, Baccelli, \& Benincasa, 2017). Sendo assim, pode-se pensar que tal fenômeno pode ser o fator que vem a promover sofrimento psíquico para o profissional de enfermagem mediante a separação do paciente. Uma vez que dado o cuidado/vínculo estabelecido, constrói-se uma espécie de "dependência" entre a díade "paciente/enfermeiro".

Para fins de exemplificação, pode-se citar as falas a seguir:

"Não é fácil, a gente começa a ter muito vínculo com o paciente. Que nem eu trabalhei 4 anos no setor de quimioterapia, então, no setor de quimio a gente tem muito vínculo, porque o paciente vem todo dia ou toda a semana ou todo mês, ele está ali. Você acompanha e muitas vezes esse processo não é bom e ele não vai atingir a resposta esperada, então é ruim." (P.).

"Eu sofro mais com aqueles que sou mais apegada, porque, sempre tem aquele que tem um carinho maior por você, e você por ele tem mais afinidade, e você acaba sofrendo com esses também, bem mais." (M.).

Por fim, cabe salientar que além da angústia da perda do objeto amado, aqui representado pelo vínculo construído com o paciente, existe outro tipo de angústia presente nos contextos que envolvem circunstâncias de limitação e impotência: a angústia de castração, 
ou seja, medo de ser separado do objeto que ama (os pacientes). Esta permanece estreitamente relacionada a situações de doença, hospitalização e sofrimento físico imposto pelo tratamento (como injeções, intervenções cirúrgicas, curativos etc.) (Ferracioli et al., 2017; Gonçalves, 2001; Rocha et al., 2017).

\section{Sentimentos experimentados por profissionais de enfermagem mediante a finitude dos pacientes oncológicos}

Nesta categoria, serão analisados os principais sentimentos vivenciados por profissionais de enfermagem mediante ao processo de finitude do paciente em tratamento oncológico, para tanto, serão também apresentadas as principais formas de defesa utilizadas pelos mesmos no manejo dos procedimentos junto a estes.

Assim, no exercício do cuidar, o profissional da saúde desenvolve pensamentos e sentimentos em relação ao sofrimento do paciente. Desta feita, o que é produzido neste entre, na relação para com o outro (paciente) se assinala na possibilidade de tocar e pelo outro ser tocado, o que na proximidade com a crise existencial e a finitude do outro também pode mobilizar e produzir sofrimento, ou até mesmo adoecimento em quem cuida (Benites et al., 2017; Leshan, 1991). Contudo, é interessante salientar que no processo do cuidar é fundamental que os mesmos saibam nomear o que sentem, o que pensam e o que desejam quanto ao tratamento dos pacientes, bem como as formas que atuam mediante ao manejo dos procedimentos junto a estes (Rocha et al., 2017; Santana et al., 2018).

No tocante aos sentimentos vivenciados, os(as) enfermeiros(as) participantes deste trabalho apontaram em sua maioria sentir a morte de seus pacientes como um "alívio", no sentido de compreender que tal fenômeno pode servir como uma "passagem" deste contexto para um outro que não dará continuidade ao "sofrimento" vivenciado pelo paciente.

Tal afirmativa, pode ser identificada nos discursos que serão apresentados a seguir:

"Diante da morte muitas vezes, a gente fala graças a Deus! Por que a gente sofre com eles, com a família principalmente. Hoje mesmo a gente ficou sabendo de um paciente que morreu esta noite passada de leucemia, a gente falou graças a Deus! Por que já estava cheio de tumores, não tava respondendo a tratamento nenhum, não tinha doador para ele de medula na família. A família toda fez o teste e não deu, então você fala graças a Deus que morreu, porque também não é vida." (C.).

"É ruim ainda a gente ter a perda do paciente, só que tem casos que quando acontece a gente pode ver até como o fim de um sofrimento, um alívio para o paciente.” (P.).

Rev. Psicol Saúde e Debate. Out., 2021:7(2): 236-252. 
Observou-se que os participantes, acreditam que a morte para os pacientes pode de algum modo significar "alívio", porém tal crença parece ser uma defesa que encontraram para lidar com a realidade de modo mais "leve". E em conseguinte lança-se mão de mecanismos de defesa em forma de racionalização como uma possibilidade de enfrentamento mediante a realidade vivenciada. Entretanto foi possível verificar que há uma acentuação deste mecanismo no que tange as reações frente ao processo de morte dos pacientes por parte das mulheres, já que 06 entre as 08 entrevistadas trouxeram conteúdos relacionados a esta temática.

Para fins de explicação, Neme (1999), afirma que a racionalização é um processo pelo qual o sujeito procura apresentar uma explicação coerente do ponto de vista lógico, ou aceitável do ponto de vista moral, para uma atitude, uma ação, uma ideia, um sentimento, dentre outros, cujos motivos verdadeiros não percebem; fala-se mais especialmente da racionalização de um sintoma, de uma compulsão defensiva, de uma formação reativa.

Neste sentido, Carvalho (2003) e Campos (2013), levam a compreender a racionalização como uma forma de substituir por boas razões uma determinada conduta que exija explicações, de um modo geral, da parte de quem a adota. Os psicanalistas, em tom jocoso, dizem que a racionalização é uma mentira inconsciente que se põe no lugar do que se reprimiu (Andrade et al., 2020). Ainda vale ressaltar que esta racionalização esteve veiculada a um discurso religioso, como se observa:

"Diante da morte muitas vezes, a gente fala graças a Deus! Por que a gente sofre com eles, com a família principalmente. Hoje mesmo a gente ficou sabendo de um paciente que morreu esta noite passada de leucemia, a gente falou graças a Deus! (...)" (C.)

Eu acho que nessa vida cada um cumpre o que tem que cumprir aqui na terra e quando chega a hora a gente tem que encarar mesmo." (C.).

Nesses trechos oras o componente espiritual é referido à figura divina como uma tentativa de racionalizar a morte considerando esta como um descanso, oras se apresenta como uma destinação, a realização de uma missão ao se fazer menção ao sujeito ter de cumprir algo na terra para concluir a sua existência. Da mesma forma em uma pesquisa realizada com enfermeiros(as) oncológicos do estado de Pernambuco esses apontaram a importância da espiritualidade como um mecanismo que possa facilitar a superação, a se lidar com situações extremas da existência, tais como a morte (Maciel, Alexandre, Ferreira, \& Silva, 2018). Ao mesmo tempo esta concepção da espiritualidade é algo que pode permear a vida do paciente e de seus familiares e assim, ser tomada como uma estratégia de enfrentamento do 
paciente que também pode ser assumida pelo enfermeiro como uma forma de alento para si (Danda Sampaio \& Heckler de Siqueira, 2016; Maciel et al., 2018).

Destarte, pode-se compreender o recurso da espiritualidade, como uma tentativa de simbolização do vivido, que a morte e o morrer podem ser reconhecidos como naturais, e por meio disso, se tornar viável seguir com o seu existir, com o seu trabalho, para o qual constantemente acabará se havendo com a finitude materializada sobre aquele à quem o profissional da saúde dispende cuidado. Além disso, a partir dos discursos apresentados pelos(as) participantes, pode-se pensar que um sentimento que se evidencia mediante a morte dos pacientes seria o desconforto, visto que trouxeram também sentimento de tristeza e impotência mediante a passagem dos pacientes, conforme se verifica.

"Quando a gente percebe que o paciente não vai sobreviver e está investindo todas as forças, todo conhecimento, é um sentimento de impotência né? Um sentimento de derrota que traz pra gente muito desconforto, desanimo muitas vezes né? e tristeza né, acabo ficando também muito triste e sofrendo junto com o paciente." (R.).

"Um obstáculo também pra gente enfrentar a morte do paciente, para gente que trabalha na área, é a família! Porque ás vezes o paciente já está naquela fase de aceitação da terminalidade e a família não acompanha os mesmos passos do paciente então, você não consegue ter o mesmo diálogo com o paciente e com o familiar, aí você tem que ter dois eixos de conversas, direcionar a conversa de forma diferente com familiar e com o próprio paciente, isso é um obstáculo." (T.).

Os achados deste trabalho vieram a corroborar com o que também foi encontrado nos estudos de Sanches (2007) e Mota et al. (2011), os quais acreditam que pode se compreender que embora a morte seja parte do ciclo natural da vida, os profissionais da enfermagem, geralmente, se colocam de modo angustiado mediante a esta, devido experimentarem uma sensação de frustração profissional/pessoal. No entanto, é possível compreender que tal angústia é suscitada no profissional devido ao medo de identificarem a si mesmos, ou algum ente familiar vivenciando a mesma situação. Conforme pode se verificar nos discursos que seguem.

"Lógico que tem frustrações principalmente quando o paciente é mais jovem que a gente compara com a nossa idade, fica aquele sentimento, aquela sensação de angústia de impotência, mas é uma coisa que consigo lidar bem, mas não sei se fosse alguém da minha família porque eu ainda não tive essa experiência. Então pode ser que eu não consiga lidar." (F.). 
"A minha maior limitação é com perdas de crianças e de pessoas mais jovens, não viveram todas as fases da vida, o que pode vir a interferir no meu cuidado, mas eu tenho que lutar contra isso." (R.).

Embora os(as)participantes apresentem sinais inerentes a sofrimento mediante a morte dos pacientes, ao contrário do que aponta Braitt Lima e Rosa (2008), que acredita que do confronto com a morte surgem frequentemente mais problemas psicológicos do que físicos na vida dos enfermeiros. Os participantes deste estudo não trazem conteúdos de adoecimento psíquico. Sendo assim, pode-se compreender que o sofrimento para estes não se configura como adoecimento, pois veem na profissão uma possibilidade de transformação de suas próprias existências. A este modo Dejours (2012) revela que o trabalho vivo consiste não apenas em produzir, mas também em transformar o existir do próprio sujeito trabalhador, ao modo como demonstraram vivenciarem os(as) participantes deste estudo.

\section{CONSIDERAÇÕES FINAIS}

Embora seja a morte um fato comum e inevitável ao longo do ciclo vital, este estudo aponta que para os(as) enfermeiros(as) participantes que exercem função junto a pacientes oncológicos tal vivência ainda significa algo penoso. Tendo em vista que nos achados desta pesquisa, compreende-se que os mesmos mediantes ao fenômeno experimentam sentimento de tristeza, angústia e frustração. Entretanto, tais sentimentos podem ser explicados pela via da identificação, já que ao longo dos discursos os(as) profissionais deram a compreender que a morte de pacientes "mais jovens" é o que mais os(as) "incomoda". A este modo, pode se pensar que inconscientemente podem se colocar no lugar destes, ou cogitarem a possibilidade que um membro de suas famílias futuramente também poderá encontrar-se neste mesmo processo. Sendo assim, o que era para ser uma vivência "esperada" em suas trajetórias devido a carreira, torna-se um promotor de sofrimento de ordem pessoal/profissional.

Os(as) participantes apontaram o vínculo constituído ao longo do processo de tratamento com o paciente como sendo algo favorável no que tange ao manejo, porém salientam que a perda de quem já são "mais vinculados(as)", traz a eles(as) mais "angústias", visto que diante do vazio deixado pelo sujeito, os(as) mesmos(as) questionam-se sobre "o que mais poderiam ter feito". Considerando que se sabe que a ciência evoluiu, no entanto não ao ponto de inibir a perda, o que os(as) fazem-se tornarem "impotentes", já que o desejo fantasioso/esperado é controlar a patologia, para que assim sintam-se potentes/preenchidos(as) pela "vitória" de terem "vencido" o "(in)vencível". 
Contraditoriamente, ainda em relação aos sentimentos vivenciados, os(as) profissionais afirmaram em sua maioria experimentar a morte de seus pacientes como um "alívio", no sentido de compreender que tal fenômeno pode servir como uma "passagem" deste contexto para um outro que em suas fantasias não irão continuar "sofrendo" já que mediante ao tratamento, estes continuamente passam a vivenciar devido aos procedimentos invasivos. Entretanto, esta afirmativa é mais uma defesa racionalizada para inconscientemente justificarem a dor da perda, já que se encontram impotentes quanto ao fato imponderável da morte de seus pacientes e para tanto, lançam mão da espiritualidade como uma sustentação frente ao que não se tem controle.

Contudo, em seus discursos, os sujeitos referiram, que ao aprofundar-se na carreira, no sentido dos procedimentos e da realização dos manejos, o morrer passa a ser visto como algo "natural", porém percebe-se que não se tornam (in)sensíveis, visto que o que passam a fazer é separar o lugar de pessoas do de profissionais. Tal posicionamento vem permeado por defesas psíquicas, uma vez que demonstraram racionalizarem a perda, em detrimento do sofrimento vivenciado. Contudo, vale salientar que tal aprendizagem, conforme já pontuado anteriormente pode ser fruto de uma exigência inconsciente que experimentam devido a profissão, que conforme sinalizam os(as) participantes, faz com que tenham que "continuar", uma vez que mesmo "morrendo" um paciente e sendo algo "triste", outros pacientes "virão e é para estes que precisam "continuarem". Assim, dada aprendizagem vem como uma representação racionalizada de um desejo de continuidade, uma vez que mesmo em sofrimento, onipotentemente passam a cobrarem-se inconscientemente por melhores resolutividades/profissionalização.

Sendo assim, salienta-se que mesmo encontrando-se "muitas vezes" mediante ao sofrimento da perda, os(as) enfermeiros(as) não se limitam em seus fazeres profissionais, bem como não demonstram adoecerem psicologicamente conforme alguns estudos aludem. Desta forma, fica claro que para estes(as) trabalhadores(as) o fato de sofrer, não necessariamente irá se configurar em adoecimento.

Cabendo aqui acrescentar que o fato de utilizarem defesas psíquicas, não os fazem apontarem traços psicopatológicos, ao contrário, esclarece o quanto desejam possuir uma vida plena, seja na ordem do pessoal, ou mesmo do profissional.

Diante desta reflexão, pode-se dizer que por este ser um estudo que realizou uma pesquisa de campo, é possível pensarmos que os achados têm uma maior relevância no contexto acadêmico, já que não são suposições levantadas a partir de outras teorias já existentes. Dando assim, possibilidades para construção de novas hipóteses teóricas inerentes 
a temática. Uma vez que os sentimentos identificados nos relatos dos sujeitos, apresentam-se como manifestações únicas e irrepetíveis, sendo assim, podem contribuir para uma ampliação das reflexões no contexto conceitual.

Vale destacar, que mesmo tendo informações de que a morte e o processo de morrer são fenômenos que despertam em profissionais de enfermagem diversos sofrimentos psicológicos, ainda assim não há grandes produções científicas que privilegiem esta temática. Desta forma, este estudo pode servir como uma provocação a que os profissionais venham a refletir sobre o tema, mas também para que se proponham a desenvolver novos estudos, já que os resultados que por este se apresentam podem servir de base para aprofundamentos futuros.

\section{REFERÊNCIAS}

Aguiar, I. R., Veloso, T. M. C., Pinheiro, A. K. B., \& Ximenes, L. B. (2006). O envolvimento do enfermeiro no processo de morrer de bebês internados em Unidade Neonatal. Acta Paulista de Enfermagem, 19(2), 131-7. https://doi.org/10.1590/S0103-21002006000200002

Andrade, C. J., Baccelli, M. S., \& Benincasa, M. (2017). O vínculo mãe-bebê no período de puerpério: uma análise winnicottiana. Vínculo, 14(1), 1-13. http://pepsic.bvsalud.org/scielo.php?script=sci_arttextpid=S1806-24902017000100004lng= ptnrm=isso

Andrade, C. J. Galhardi, S. R. R. B., \& Avoglia, H. R. C. (2020). Reações defensivas de pacientes em tratamento oncológico: análise das principais formas de enfrentamento. Brazilian Journal of Health Review, 3, 5881-5899. https://doi.org/10.34119/bjhrv3n3-149

Benites, A. C, Neme, C. M. B., \& Santos, M. A. (2017). Significados da espiritualidade para pacientes com câncer em cuidados paliativos. Estudos de Psicologia (Campinas) , 34, 269279.

Bezerra, J. S., Freitas, K. S., Góis, J. A., Lima, A. B., Fontoura, E. G., \& Oliveira, M. A. N (2019). Validação de cartilha para promoção do conforto de familiares com parentes hospitalizados. Revista da Rede de Enfermagem do Nordeste, 20, e41399.

Bleger, J. (2007). Temas de psicologia: entrevista e grupos (3a ed.). São Paulo: Martins Fontes.

Bosco, A. G. (2008). Perda e luto na equipe de enfermagem do centro cirúrgico de urgência e emergência (Tese de Doutorado). Escola de Enfermagem de Ribeirão Preto/USF, Programa de Pós-Graduação em Enfermagem Psiquiátrica, Ribeirão Preto.

Braitt Lima, A. \& Santa Rosa, D. O. (2018). Guia para o processo de ajuda interpessoal de enfermagem ao familiar do paciente crítico. CIENCIA Y ENFERMERÍA (EN LÍNEA), 23, 159169. http://dx.doi.org/10.4067/S0717-95532017000200159

Rev. Psicol Saúde e Debate. Out., 2021:7(2): 236-252. 
Bretas, J. R. S., Oliveira, J. R., \& Yamaguti, L. (2006). Reflexões de estudantes de enfermagem sobre morte e o morrer. Revista da Escola de Enfermagem da USP, 40(4). Recuperado em 10 out. 2017, de <http://www.scielo.br/scielo.php?script=sci_ arttext\&pid=S0080$62342006000400005 \& \operatorname{lng}=$ en\& $\mathrm{nrm}=$ iso $>$.

Brito, S., \& Carvalho, V. B. (2017). O cuidar no processo de morrer na percepção da mulher das mulheres com câncer: uma atitude Fenomenológica. Düsseldorf, Alemanha: Novas Edições Acadêmicas.

Campos, É. B. V. (2013). Considerações sobre a morte e o luto na psicanálise. Revista de Psicologia da UNESP, 12(1), 13-24.

Carvalho, M. M. J. (Coord.). (2003). Introdução à psicooncologia. Campinas: Livro Pleno.

Danda Sampaio, A., \& Heckler de Siqueira, H. C. (2016). Influência da Espiritualidade no Tratamento do Usuário Oncológico: Olhar da Enfermagem. Ensaios e Ciência: Ciências Biológicas, Agrárias e da Saúde, 20(3), 151-158. Recuperado em 20 set. 2021, de $<$ https://seer.pgsskroton.com/index.php/ensaioeciencia/article/view/4433 >.

Dejours, C. (2012). Trabalho vivo: trabalho e emancipação (Vol. 2). Brasília: Paralelo 15.

Ferracioli, N. G. M., Vendruscolo, J., \& Santos, M. A. D. (2017). Quando a psicanálise entrou no centro cirúrgico: um relato de experiência. Vínculo (São Paulo), 14, 1-12.

Ferreira, V. S., \& Raminelli, O. (2012). O olhar do paciente oncológico em relação a sua terminalidade: ponto de vista psicológico. Revista da Sociedade Brasileira de Psicologia Hospitalar, 15(1), 101-113. Recuperado em 02 out. 2017, de http://pepsic.bvsalud.org/scielo.php?script=sci_arttextpid=S151608582012000100007 Ing $=$ ptnrm $=$ iso $>$.

Gomes, G.C., Xavier, D. M., Mota, M. S., Salvador, M.S., Silveira, R.S., \& Barlem, E. L. D. (2014). Dando notícias difíceis à família da criança em situação grave ou em processo de terminalidade. Revista Enfermagem UERJ, 22, 347-352. Recuperado em 02 out. 2017, de https://www.e-publicacoes.uerj.br/index.php/enfermagemuerj/article/view/13723

Gonçalves, M. O. (2001). Morte e castração: um estudo psicanalítico sobre a doença terminal infantil. Psicologia Ciência e Profissão, 21(1), 30-41. https://doi.org/10.1590/S141498932001000100004

Kübler-Ross, E. (2008). Sobre a morte e o morrer: o que os doentes terminais tem para ensinar aos médicos, enfermeiras, religiosos e aos próprios parentes. (P. Menezes, Trad.) (9a ed.). São Paulo: WMF Martins Fontes.

Leshan, L. (1992). O câncer como ponto de mutação. São Paulo: Summus.

Braitt Lima, A. \& Rosa, D. O. S. (2008). O sentido da vida do familiar do paciente crítico. REE Revista da Escola de Enfermagem da USP, 42(3) 574-553. https://doi.org/10.1590/S008062342008000300019 
Braitt Lima, A. \& SANTA ROSA, D. de O. (2017). Significados da responsabilização pelo cuidar/cuidado por estudantes de enfermagem um estudo fenomenológico. ETICA DE LOS CUIDADOS , 9. Recuperado em 20 jun. 2018, de https://dialnet.unirioja.es/servlet/articulo?codigo $=7500028$

Maciel, A. M. S. B., Alexandre, A. C. S., Ferreira, D. M. B, \& Silva, F. C. (2018). A condição da espiritualidade na assistência de enfermagem oncológica / The condition of spirituality in oncological nursing care. Revista de Enfermagem da UFPE online, 12(11): 3024-3029. $\begin{array}{llll}\text { Recuperado em } 20 & \text { set. } & \text { 2021, }\end{array}$ <https://periodicos.ufpe.br/revistas/revistaenfermagem/article/view/234609/30497>.

Mota, M. S., Gomes, G. C., Coelho, M. F., Lunardi, W. D. F., \& Sousa, L. D. (2011). Reações e sentimentos de profissionais da enfermagem frente à morte dos pacientes sob seus cuidados. Revista Gaúcha de Enfermagem (Online), 32(1). http://dx.doi.org/10.1590/S1983-14472011000100017

Neme, C. M. B. (1999). Enfrentamento do câncer: ganhos terapêuticos com psicoterapia num serviço de psico-oncologia em hospital geral (Tese de Doutorado). Pontifícia Universidade Católica, São Paulo.

Rocha, D. D., Nascimento, Ê. C., Raimundo, L. P., Damasceno, A. M. B., \& Bondim, H. F. F. B. (2017). Sentimentos vivenciados pelos profissionais de Enfermagem diante de morte em unidade de terapia intensiva neonatal. Mental, 11(21), 546-560. Recuperado em 27 de junho de 2021, de http://pepsic.bvsalud.org/scielo.php?script=sci_arttext\&pid=S1679$44272017000200015 \&$ Ing=pt\&tlng=pt.

Sanches, P. G. (2007). Convivendo com a morte e o morrer: o ser-enfermeiro em unidade de terapia intensiva (Dissertação de Mestrado). Universidade Estadual de Maringá, Maringá.

Santana, J. C. D., Andrade, C. J., \& Carvalho, M. V. B. (2018). A morte na perspectiva de enfermeiros oncológicos: análise das repercussões na saúde mental destes profissionais. In: Cristiano de Jesus Andrade. (Org.). Saúde mental e trabalho: temas emergentes na contemporaneidade. 1ed.Curitiba: CRV, 1, 137-150.

Turato, E. R. (2003). Tratamento da metodologia da pesquisa clínico-qualitativa: construção teórico-epistemológica, discussão comparada e aplicação nas áreas da saúde humanas. Rio de Janeiro: Vozes.

Vizzotto, M. M. (2003). O método clínico e as intervenções na comunidade. In: V. B. Oliveira, \& K. Yamamoto (Orgs.), Psicologia da saúde: Temas, reflexão e prática (pp. 137-152). São Bernardo do Campo: Metodista. 